\title{
El barco como objeto artístico y viaje alegórico: la galera real de Lepanto
}

\author{
María Dolores Aguilar García
}

Esta nave puede entenderse como un palacio flotante ${ }^{1}$ decorado con temas mitológicos y alegóricos tan gratos a la cultura humanistica. Toda su ornamentación se hizo según el programa de Juan de Mal Lara ${ }^{2}$, del que entresacamos significativos ejemplos de viajes y viajeros, ilustres ejemplos del pasado, interpretados en clave de presente. Constituye un claro ejemplo de literatura moralizante, a base de emblemas, cuya iconografía serviría de guía para el trabajo artístico del escultor Juan Bautista Vázquez y del pintor Cristóbal de las Casas.

\section{LA PROA $^{3}$}

Las arrumbadas de proa se proyectan con cuadros de pintura inspirados en la Eneida y la Odisea. A la derecha Eneas dormido en la proa de una galera mientras un Mercurio por el aire le dice ¿Puedes dormir

\footnotetext{
1 De esta galera nos ocupamos anteriormente en el Simposio Nacional de Historia del Arte "El barco como metáfora visual y vehículo de transmisión de formas" Málaga-Melilla. octubre 1985, con la comunicación: "El barco como Palacio Flotante: la Galera Real de Lepanto", pág. 339.

${ }_{2}$ Descripción de la Galera Real del Serenísimo D. Juan de Austria. Sevilla. Bibliófilos Andaluces, 1876.

${ }_{3}$ La reconstrucción a tamaño natural realizada en 1971 de esta galera en el Museo Marítimo de Barcelona ha sido de gran ayuda para estos trabajos.
} 
tranquilo? («Potes sub casu ducere somnos»). Todos los mensajes alegóricos de la nave vienen encaminados a servir de espejo de virtud para el General de la Armada D. Juan de Austria. Así, en este caso, se le advierte de su actitud activa ante el peligro de los turcos. Eneas además en esta escena ${ }^{4}$ abandona Cartago camino de Roma, donde culminará su empresa de ser Padre de un pueblo. Hay un mensaje no literal, en el ejemplo que se elige, aludiendo tácitamente al destino honroso del capitán D. Juan, vinculado con acontecimientos políticos e históricos del momento ${ }^{5}$.

En la arrumbada izquierda, Ulises con Circe mostrándole el paso entre Scila y Caribdis ${ }^{6}$ con el sentido de elegir entre dos males, el menor ${ }^{7}$. El mote "Inter utrunque vola" (vuela entre ambos peligros), se aplica a la Victoria sobrevolando dos contendientes ${ }^{8}$, que el autor emplea con toda libertad como lo hará en otros casos (Fig. 1).

Ulises prudentemente elige un peligro que considera menor. De la misma manera presentar la guerra a los turcos será un riesgo más pequeño que detenerse. No obstante se adivina la victoria y el deseo de un feliz regreso.

En la Banda izquierda o de babor ${ }^{9}$ un término ornamental, de nuevo se referirá a Ulises, esta vez en el momento en que se ata al mástil del barco para no sucumbir ante los encantos de las sirenas con el mote "Me dulcia laedant" (por que lo dulce no haga mal) con el sentido moral de que los momentos dulces después producen dolor. El emblema lo toma de Alciato ${ }^{10}$ combinándolo con el mote de otro ${ }^{11}$, aunque con variantes, referido a Cupido cuando va a coger la miel y vuelve lleno de picaduras (Fig. 2).

4 Libro IV. Eneida.

4 P. Aguado Bleye, Manual de Historia de España. Madrid. Ed. Espasa Calpe. 1959, vol. II, pág. 606. La Liga Santa receló siempre de Felipe II sospechando que pretendía fundar un reino en Albania y Dalmacia, una vez conquistadas por su hermano D. Juan.

6 Descripción... obra citada, pág. 152.

- Ulises elige el paso entre Sicilia y Caribdis frente a las Rocas Errantes. Odisea. Libro XII.

8 Gabriel Rollehangen, Nucleus Emblematum, 1611. Tomado de Henkel y Schone, Emblemata. Metzlersche. Sttutgart, 19, n. ${ }^{\circ}$ 1.564. Año 1967.

9 Descripción... obra citada, pág. 135-142. En estas páginas se hace un erudito resumen de la Odisea.

10 Alciato, Emblemas. Edición de Santiago Sebastián. Madrid. Ed. Akal, S.A., 1985, Emblema CXV, pág. 152.

" Ibidem, obra citada Emblema CXI, pág. 147 «Dulcia quadoque amara fieri». 
En la proa, pues, se reúnen dos grandes viajeros; uno, fundador de un pueblo; otro, espejo moral de virtud marina.

\section{LA POPA}

El castillo de popa se destina a estancia de D. Juan, por lo que se decora con particular atención erudita. En el interior, con complejos programas y resortes psicológicos para el hombre del Renacimiento: hombres llustres, Estaciones, Constelaciones, etc. En el exterior de la media popa, conciliando virtudes cristianas con el tema mítico de un viaje: los Argonautas, "puesta la memoria de tan antigua y famosa empresa encima del gobierno de toda la galera" ${ }^{12}$. Ocupaba el lugar más visible para toda la armada, al situarse como galera capitana al frente de ella. Las virtudes programadas fueron ${ }^{13}$ :

La Prudencia, como doncella portando un espejo ${ }^{14}$.

La Templanza, como un vaso en cada mano ${ }^{15}$.

La Fortaleza, con una columna ${ }^{16}$.

La Justicia, con peso y espada ${ }^{17}$.

Las virtudes iban esculpidas en relieve según la iconografía tradicional. Entre ellas, cuadros de pintura descritos según la literatura emblemática de la época, dando un valor moral a cada escena extraida del repertorio narrativo de la Argonáutica ${ }^{18}$ (Fig. 3).

12 Descripción..., obra citada, pág. 89.

13 Ibidem, obra citada, pág. 24.

14 Ripa, Iconografía, Zurich. N. York. Hildesheim. 1984, pág. 416-417.

15 Ibidem, obra citada, pág. 482, en la mano izquierda lleva un vaso y en la derecha una tenaza candente que enfría en el vaso.

16 Ibidem, obra citada, pág. 166, porque la columna es lo más fuerte de un edificio.

17 Ibidem, obra citada, pág. 198.

18 Utiliza indistintamente las fuentes de Apolonio de Rodas: Argonáutica y de Píndaro: Pítica IV. El tema es suficientemente conocido: Jasón hijo del rey de Yolcos se considera injustamente desposeido del trono de su padre arrebatado por su tío Pelías. Éste, para alejarlo de sí, advertido por un oráculo, lo envía a buscar el vellocino de oro, piel dorada de un carnero que transportó por los aires a Frixos (Trueno) y Hella (relámpago). Frixos sacrificó el carnero a su llegada a la isla de Asa y lo entregó a su rey (hijo del sol) que lo instaló en un bosque consagrado a Marte vigilado por un dragón.

Jasón convoca a los guerreros y héroes más famosos de Grecia para que le ayuden: 
En el centro de la popa proyecta la nave Argos con las diosas Juno y Minerva y Hércules portando la clave en el borde de la nave ${ }^{19}$. Por mote "Virtute Duce comite Fortuna" (La Virtud como guía, la Fortuna compañera).

Para la nave se valió de un emblema con mote similar «Audeutes Fortuna iuvat" que lleva en la proa una diosa ${ }^{20}$. Sin embargo el mote lo utilizó para un cuadro de Alejandro Magno en la banda de estribor. Este mote empleado aparece en emblemas de la nave con los Argonautas ${ }^{21}$, de gran tradición erudita desde Cicerón y Píndaro hasta Erasmo, de quien la tomaría Mal Lara debido a sus estudios sobre este filósofo ${ }^{22}$.

La presencia de las diosas Juno y Minerva se recoge en los emblemas propugnando el éxito si se auna la Fortuna (Juno) y la Virtud (Sabiduría de Minerva) ${ }^{23}$ (Fig. 4). La Fortuna, tema muy repetido en el Renacimiento, procede de inscripciones de monedas romanas. Por si sola la Fortuna no vale nada, si no se acompaña de la Virtud. Así lo concibe Alciato ${ }^{24}$ con un mote similar "Virtute Fortunae comes» (La fortuna compañera de la virtud). Su emblema son los atributos de Mercurio y los cuernos de la cabra Amaltea (Fig. 5).

Hércules en el borde de la nave, va en representación de sus compañeros, los Argonautas. Precisamente él, que no viajó todo el tiempo en la expedición, ya que se quedó en un bosque de Misia donde desgajó de un árbol una rama para hacer su clava. Pero interesa resaltar este héroe sobre los demás, por sus especiales connotaciones hispanas, fundador mítico de la monarquia española ${ }^{25}$ y recordado en otros lugares

Hércules, Cástor y Pólux, Peleo, etc. Atenea dirige la construcción de la nave y pone en su proa la madera de encina del bosque de Dodona, de cualidades proféticas. La ruta es hacia oriente. Llegados a Colcos, Jasón realiza las pruebas de uncir a los toros salvajes, y matar al dragón con la ayuda de su enamorada Medea. El regreso también es largo pero al fin vuelven a Yolcos. El final de la historia tiene variantes: Píndaro muestra un héroe más viril. Apolodoro, un guerrero más cortesano. Su trágico fin muerto por el palo de su nave es una versión más tardía.

19 Descripción, obra citada, pág. 21-23.

20 Hyeronimus Sperling,Trojano regio Principi, 1695. Ausburgo, n. ${ }^{\circ}$. Recogido en HENKEL Y SCHONE, Emblemata, n. ${ }^{\circ} 1634$.

21 Peter IsSelbuRG, Emblemata Politica, 1568-1580, n. ${ }^{\circ}$ 9. Recogido en Emblemata, n. ${ }^{\circ}$ 1454.

22 Juan de MAL LARA, De Philosophía Vulgar. Sevilla 1568.

23 Guillaume DE LA Perriere, La Morosophie. 1.553. Recogido en Emblemata, obra citada, n. ${ }^{\circ} 1731$ (Fig. 4).

${ }^{24}$ Alciato, obra citada, pág. 156. Emblema CXVIII. De este mote se ocupó. P. Valeriano. Empresa XV-47, P. Glovio. Emblema 36.

25 Marqués de la Fuensanta del Valle, Colección de Documentos inéditos para la Historia de España. Recoge la teoría del arzobispo D. Rodrigo Jiménez de Rada. 
de esta galera siempre con ese sentido. El autor del programa evoca en los nuevos Argonautas a los conquistadores, viajeros y colonizadores españoles ${ }^{26}$ que lucharon por su patria y por su fe, quedando marcada esta zona central de claras alusiones a España, a su misión histórica y a la exaltación de sus héroes.

A la derecha, de nuevo proyecta una galera, pero pasando entre las rocas Cianeas ${ }^{27}$ y sobre ellas de nuevo las diosas Juno y Minerca con el mote "Fataviam inveniet" (Los hados encontrarán el camino ${ }^{28}$.

Recoge un episodio de la Argonáutica ${ }^{29}$ cuando la nave Argos pasa por entre las rocas Cianeas. Para ayudarles en tan difícil trance, Atenea se coloca a la salida del Bósforo sobre la costa auropea del Ponto Euxino cerca de las rocas Cianeas. La presencia de Juno, en cambio, no se registra en este episodio concreto. Pero su ayuda a los argonautas es constante debido al afecto que le profesa a Jasón y su odio por Pelias. Atenea o Minerva era la diosa tutelar de Jasón, que dirigió la construcción de la propia nave, dándole facultades prodigiosas, fuera de $10 \mathrm{co}-$ mún.

Su iconografía pudo inspirarse en el emblema de una galera pasando entre escollos ${ }^{30}$ (Fig. 6). Las diosas Juno y Minerva juntas de nuevo, reiterarian la idea de la Fortuna inseparable de la virtud. El episodio está bien elegido, incluso en el aspecto geográfico, ya que las piedras Cianeas, en la entrada de la "Sublime Puerta", son todo un símbolo y arquetipo de las dificultades que le ponen a la escuadra de la Santa Liga.

El cuadro de la izquierda se dedica a Jasón, con sus pies sobre los toros vencidos, mientras el dragón cae dormido. Jasón porta el vellocino y ante él está Medea con el mote "Hoc virtutis opus" (esto es obra de la virtud).

Covarruvias $^{31}$ (Fig. 7) trae los toros y el dragón con el sentido de buscar la eterna gloria en vez de lo caduco. Su natural libertad creativa

${ }^{26}$ Descripción..., obra citada, pág. 82.

${ }_{27}$ Las rocas Cianeas son rocas situadas a la entrada del Ponto Euxino, variante mítica de las Simplegadas, rocas que aprisionaban los barcos, en cuyo orígen quizá habrá que ver el deseo de comerciantes y aventureros de evitar la competencia.

${ }^{28}$ Reusner, Emblemata ill, n. ${ }^{\circ}$ 37. Recogido en Emblemata, $n .^{\circ} 1201$, referido a un laberinto.

29 Apolonio de RHODES, Argonautiques. Paris 1974. Canto II, verso 528 y 548.

30 Gilles CORROzET, Hecatongraphie. Paris 1543. Recogido en Emblemata, n. ${ }^{\circ} 1.467$ con el mote "Peril incogneu». (Fig. 6).

31 Covaraubias y Orozco, Emblemas morales. 1.610, n. ${ }^{\circ}$ 89. Recogido en Emblemata, 
le lleva a colocar a Medea ante él, que aquí no tiene el sentido peyorativo que la mitología le confiere, por su carácter brujeril y medio hechicera. Al contrario, porta un lema que se traduce «Esto es obra de la virtud», ligera variante de "Hoc virtutis amor" de un unicornio de Camerarius ${ }^{32}$, en el que la obra del amor se cambia por la obra de la virtud (Fig. 8).

Hay en toda la descripción de la galera una intención tácita de que no aparezca ni Venus, ni Cupido, ni mujer alguna. Incluso en el cuadro alegórico de la justicia que se proyecta en el interior de la popa, la figura femenina desnuda sobre un delfin se cambia por la de un hombre ${ }^{33}$. En el interior de la popa, donde banquete, utensilios y juego están tomados de El Sueño de Polifilo ${ }^{34}$, se emplea todo con un carácter austero, privado voluntariamente del sentido amoroso y erótico de su fuente de inspiración. Todo ello atribuible a las imposiciones de la rígida moral contrarreformista. Aquí Medea no es la heroina enamorada ni la hechicera de poderes sobrenaturales: es ejemplo del esfuerzo (virtud) no del amor. Se diría que le muestra a $D$. Juan las pruebas a seguir, como un predestinado cuyo destino es la razón de estado, siempre más fuerte que sus sentimientos, y que como a Jasón se le pone a prueba realizando empresas sobrehumanas.

Los Argonautas del mito helénico son héroes que marchan a conquistar el vellocino de oro, piel prodigiosa, objeto-clave del viaje, que supone la recuperación de un tesoro para su jefe, Jasón. Los mejores guerreros participan con la intención de establecer una especie de comunicación directa entre el mundo y el espacio divino, por eso su empresa adquiere carácter trascendente.

El vellocino, vigilado por el dragón, es recuperado por el valor del héroe que paraliza su actividad destructora. Connotaciones solares, como el oro de su vellón o la dirección siempre oriental del viaje, confieren al mito un relevante sentido cósmico. De todos ellos Jasón es un héroe predestinado que marcha hacia su inexorable destino marcado por su propia sangre real.

$\mathrm{n} .^{\circ} 1637, \mathrm{n} .^{\circ} 1639$, referido a Jasón luchando con el dragón. Tomado de REUSNER, Emblemata I, n. ${ }^{\circ} 28$.

${ }^{32}$ Camerarilis, Limbolorum emblematum II, n. ${ }^{\circ}$ 13. 1595. Recogido en Emblemata, obra citada, n. ${ }^{\circ} 422$.

${ }_{33}$ Ver mi comunicación al Simposio Nacional «El barco como metáfora visual y vehiculo de transmisión de formas" Málaga-Melilla. Octubre 1985. Con el título "El barco como palacio fotante: la Galera Real de D. Juan de Austria", pág. 339.

34 Francisco Colonna, El sueño de Polifilo. Trad. de Pilar Pedraza. Murcia 1981. 
Quizá de todos los mitos clásicos ninguno pueda adaptarse mejor a la empresa de esta guerra contra los turcos, ni tenga más fácil paralelo que éste con la figura de D. Juan. Explícitamente se le llama Nuevo Jasón ${ }^{35}$, y a $\mathrm{D}$. Juan viene a referirse tantas veces como habla del héroe mítico ${ }^{36}$ : D. Juan es el hijo pequeño de un rey poderoso, con una misión heroica y audaz que cumplir; deberá rescatar del enemigo turco un tesoro que pertenece al mundo cristiano y unirlo a las aspiraciones de imperio universal de su hermano el Rey (Fig. 10 B).

Mal Lara pretende de D. Juan el prototipo de héroe valiente según la versión de Píndaro, a que se había hecho acreedor por las numerosas empresas de responsabilidad a él confiadas ${ }^{37}$. Virtudes militares, de valor, de prudencia tantas veces probadas, no necesitaban quizá un recordatorio tan constante en cada centímetro de la galera. Por eso más bien con este despliegue iconográfico se busca el engrandecimiento de la Corona y de su hermano el Rey, que tuvo siempre recelos de él y quién sabe si todos estos cargos de responsabilidad no iban encaminados a alejarlo de sí y de la Corte ${ }^{38}$.

D. Juan es el nuevo Jasón, también a través de Medea, que aparece, casi veladamente, una sola vez. Medea, según una versión tardía ${ }^{39}$ era reina de la isla de Corinto, y Jasón la desposa convirtiéndose en príncipe consorte. En los planes de Felipe II entraba casar a su hermano con María Estuardo, reina de Escocia. Y la misma Liga Santa receló del rey español, temiendo que los territorios que se conquistaran en Macedonia y Albania fueran convertidos en un reino para D. Juan.

Mal Lara tenía una gran cultura humanística ${ }^{40}$ y estaba al tanto de muchas facetas políticas en su mundillo sevillano donde vivía. La censura inquisitorial, la razón de estado, la misma prudencia política le impediria

35 Descripción..., obra citada, pág. 20.

36 Ibidem, obra citada, pág. 76 y ss. Cuenta su historia con detalle; pág. 84-85, traduce un verso de Píndaro de la Pítica IV; pág. 311 elogio de los mejores capitanes, entre ellos de Jasón.

${ }_{37}$ P. Aguado Bleye, Manual de Historia de España. Vol. II, pág. 447. En 1569 tiene el mando de la guerra contra los moriscos sublevados. En 1568 dirige las galeras del Mediterráneo y Adriático. En 1571 está al mando de la escuadra de la Liga Santa. En 1573 conquista Túnez. En 1576 gobierna los Países Bajos.

38 Nunca le concedió tratamiento de Alteza Real, sólo Excelencia, privándole además de honores de su rango como el poder usar silla. Vid. A. AGUADo BLEYE, pág. 447.

39 Eumelo, Corintiakha. Vid C. Garcia Gual, Edición de El viaje de los Argonautas, de Apolonio de Rodas. Editora Nacional, 1975, pág. 26.

${ }_{40}$ V. Lleo Cañal, Nueva Roma. Diputación Provincial de Sevilla, 1980. pág. 177. Su bıblioteca tenía ejemplares de autores clásicos, entre ellos Aulo Gelio, Ateneo, Macrobio, etc... y numerosos libros de emblemas. 
hablar más claro, pero pocas palabras bastan: coincide incluso su trágico final:

Según un poema tardío ${ }^{41}$ Jasón murió aplastado por el palo mayor de su propio navío, el Argos. D. Juan, a los 33 años murió en los Países Bajos, admitiéndose la duda de que su muerte no se debiera a causas naturales ${ }^{42}$.

\section{OTROS ARGONAUTAS}

\section{Palas}

Aparte de la aparición de Palas con Hera en el sobre-dragante, se repite como término escultórico en la banda de estribor ${ }^{43}$ (Fig. 9), como diosa de la sabiduría y en sitio preeminente por ser clave junto con Marte del otro lado para la divisa de Hispania ${ }^{44}$ (Fig. 10). La galera en sí es un barco especial, hecho del mejor pino catalán con unas dimensiones especiales que le convierten en una galeaza (60 remos). Presidida por $\mathrm{Pa}$ las es una nueva nave Argos, que recoge a Palas en la popa, como en el cuadro del centro. El mote "Nusquam abero" (jamás te faltaré), alude a su predilecta protección.

\section{Neptuno}

Jasón, al concluir su aventura, consagró a Neptuno su navio, según la versión de Píndaro ${ }^{45}$. Neptuno aparece en el barco varias veces, en la banda izquierda ${ }^{46}$, y en el relieve de popa ${ }^{47}$, siempre en carro de

4 C. Garcli Gual, El viaje..., pág. 20.

42 A. Marañon, Antonio Pérez. Madrid. Ed. Espasa Calpe. 1977.

43 Descripción..., obra citada, pág. 37 y 97.

44 CovarRubias y Horozco, Emblemas morales. Madrid. Ed. Fundación Universitaria Española. 1978, Centuria III, n. ${ }^{\circ} 12$.

45 C. Garcia Gual, El viaje..., pág. 45.

46 Descripción..., obra citada, pág. 28.

47 Ibidem, obra citada, pág. 62 y 146. 
caballos marinos ${ }^{48}$ (Fig. 9). Sin embargo el más relacionado con toda esta empresa puede ser el Neptuno sobre delfín de la proa, que significa Neptuno en el poder, delfín en la presteza. Su presencia en el espolón de proa equivale a un señorio sobre la nave, dominador del mar con la rapidez del delfín (Fig. 11).

\section{Hércules}

El héroe, asociado a toda empresa hispana aparece varias veces. Ya hemos comentado su presencia en el sobrecargante de popa. De nuevo aparece en el relieve que corona la popa, al que el autor le llama el Huerto ${ }^{49}$. El dragón vencido dice que es hermano del dragón que defendía el vellocino en Colcos. Aquí aparece un episodio que se cita en la Argonáutica: el jardín de las Hespérides ${ }^{50}$ y la intervención de Hércules, asociado a una empresa tradicionalmente ibérica (Fig. 12).

Hércules, el dragón, la nave Argos consagrada por Palas, fueron dignos de estar entre las estrellas, y así se les cita en la descripción del techo de la estancia de D. Juan ${ }^{51}$.

\section{Cástor y Polux}

Los dos hermanos gemelos aparecen varias veces, siempre referidos al paralelismo entre ellos y los dos hermanos Felipe II y D. Juan.

En el interior de la cámara de popa se decoran las barcazas entre otros, con un cuadro de Neptuno (que alude a Carlos $V$ ) y acompañado de "dos niños abrazados, que son las estrellas Cástor y Polux" 52.

Carlos $V$ como dios del mar, alude a sus empresas marítimas, militares y colonizadoras, inspirado quizá en el emblema ${ }^{53}$ al que se añaden

${ }_{48}$ Bartolomeus Anulus, Picta Poiesis ut pictura poiesis, $1552, n .{ }^{\circ} 37$. Recogido en Emblemata, n. ${ }^{\circ} 1599$.

49 Descripción..., obra citada, pág. 162-165.

so Canto IV. Verso 1.400. Vid. C. Garcia Gual, El viaje...

51 Descripción..., obra citada, pág. 445 y ss.

52 Ibidem, obra citada, pág. 173.

53 Bartolomeus Anulus, Picta Poiesis..., obra citada, n. ${ }^{\circ}$ 37. Recogido en Emblemata, 1599. 
nuevos detalles como los hermanos abrazados en el cielo, tal como aparece en Hernando de Soto ${ }^{54}$ (Fig. 13) o como dos estrellas, empleado en Alciato ${ }^{55}$, signo que vuelve la calma al mar y por tanto emblema de la esperanza (Fig. 14).

Cástor y Polux, ejemplo de amor fraterno, tal como aparecen siempre en la emblemática ${ }^{56}$, de igual forma intervienen en otras ocasiones en la decoración de la nave:

En la descripción del signo de géminis ${ }^{57}$ son dos mozos enlazados por el hombro. Uno coge una hoz en la mano, otro una estrella. La iconografía parece más bien invención del autor, no exenta del sentido constante que desea darle: D. Juan porta la hoz de su esfuerzo, del trabajo de sus numerosas empresas, pero comparte fraternalmente la gloria con su hermano, que alcanza su destino en forma de estrella. El mote que utiliza es "Cum duo coniuncti veniunt, victoria certa est" (cuando dos vienen juntos, la victoria es cierta), tomado de Alciato ${ }^{58}$ que pone de manifiesto la misma idea, prudencia y valor, aplicados a Felipe II y D. Juan respectivamente (Fig. 15).

El signo de géminis toma voz en un vaticinio que los astros le hacen al capitán ${ }^{59}$ con este verso:

"Cuando dos vinieren en compañia siendo poderosos los enemigos mueren quedando perdidos contra los dos Hermanos venturosos"

De nuevo la alegoria, esta vez como nuevos argonautas.

54 Emblemas Moralizadas, 120. Recogido en Emblemata, 956.

55 Emblema XLIII. Edición de Santiago Sebastián, pág. 78-79.

s6 Emblemata..., obra citada, pág. 1675-1676.

${ }^{57}$ Descripción..., obra citada, pág. 421.

58 Ibidem, , obra citada, pág. 491.

59 Ibidem, obra citada. 


\section{OTROS ARGONAUTAS}

En un programa iconográfico tan amplio, plagado de citas clásicas, dioses y héroes, es natural encontrar la presencia de otros personajes mitológicos que participaron en el viaje de los Argonautas, aunque en el contexto del barco no se relacionen con el poema. Así Apolo, protector de las expediciones ${ }^{60}$, que intervino en una tempestad salvando la nave Argos antes de llegar a Egina, vendrá en el relieve del sobredragante con otros dioses. Su iconografía es sobre un carro y con la cabeza llena de rayos, como en la constelación del Apolo, como Dios-Sol.

Orfeo realiza su tradicional oficio: tocar la lira ${ }^{61}$ en la ornamentación del vaso de almibar en el banquete ${ }^{62}$. Orfeo tiene varias intervenciones en la Argonáutica: tañendo la lira y salvando a sus viajeros de las peligrosas habitantes de Lemnos ${ }^{63}$ y convenciendo a las celosas guardianas del jardín de las Hespérides para que les mostrasen una fuente para proveer de agua la nave.

Perseo aparece como término escultórico en la banda lateral derecha, con Medusa en la mano ante el mar de Suria con 3 altares y el mote "Donat omnia virtus" ${ }^{64}$ (La Virtud lo da todo).

La descripción de Perseo-Constelación la toma de Manilio según confiesa, y lleva coraza, alas en los pies, celada en la cabeza, escudo, alfange y la cabeza de Medusa como aparece en Emblemata ${ }^{65}$.

Peleo, padre de Aquiles, vencedor de Troya, viene en el relieve de popa ${ }^{66}$. Era el cómitere de la nave Argos, y su presencia aquí es más simbólica que real como Argonauta: se relaciona con el peligro oriental, como Troya para los griegos, así son los turcos para la cristiandad. El final feliz de la guerra de Troya es espejo de un final venturoso para esta intervención bélica. Supone pues una especie de justificación de la guerra.

60 Argonáutica. Canto I. Vid. C. Garcia Gual, El viaje..., pág. 49.

Emblemata..., obra citada, pág. 1609-1610.

Descripción..., obra citada, pág. 290.

63 Argonáutica. Canto I. Verso 609-909. Vid. C. Garcli GuAL, El viaje..., obra citada, pág. 33.

64 Con sentido similar en Achilles Bocchus, Simbolicarum quaetorum de universo, 1555. Recogido en Emblemata, 1666 con el mote "Sic monstra vitios, domat Prudentia".

651665 de la obra de B. Anulus: Picta Poiesis..., obra citada 1552, n. 10.

${ }_{65}$ Descripción..., obra citada, pág. 61. 
La Argonáutica relata otra serie de episodios que vienen recogidos de mitos anteriores: así, durante su paso por el Cáucaso ven a Prometeo atado a una Peña, comidas sus entrañas por un águila ${ }^{67}$. De igual manera aparece en la banda de babor como término escultórico cuya iconografía saca de Alciato ${ }^{68}$.

Pasan también por la tierra de las amazonas, que tienen un cuadro de pintura en la banda de estribor ${ }^{69}$. Alude a los pájaros Alciones, como augurio de una feliz navegación ${ }^{70}$ con el mismo sentido que en el poema de Apolonio ${ }^{71}$.

En el viaje de vuelta, ya de regreso a Yolcos, vadean el Eridano (río Po) que aparece también mencionado entre las construcciones ${ }^{72}$.

Estos últimos personajes, episodios y lugares, van mezclados con otros temas, por lo que sólo en la popa puede establecerse una secuencia continua inspirada en la Argonáutica. Sus paralelismos con otros lugares de la nave son debidos al uso constante de Apolonio y Píndaro como fuentes de inspiración.

\section{CONCLUSIONES}

La ornamentación de la Galera Capitana se hace en base a numerosas fuentes clásicas y renacentistas. De todas ellas el tema de viaje viene dado por ilustres obras como La Odisea, La Eneida y sobre todo La Argonáutica.

La insistencia en esta última se debe a los paralelismos que pueden establecerse, mejor con ella que con otras fuentes, entre el pasado como espejo heroico de virtudes y el presente inmediato.

Coincide hasta en detalles geográficos como las piedras Cianeas a la entrada del Ponto Euxino, corazón del imperio turco, e incluso crono-

\footnotetext{
67 Apolonios de Rhodes, Argonautiques, París 1974, pág. 174.

68 Alciato, Emblemata..., obra citada, Emblema ClI, pág. 136.

69 Canto II. Verso 911. C. Garcia GuAL, El viaje..., obra citada, pág. 36.

Descripción..., obra citada, pág. 45.

Descripción..., obra citada, pág. 30-31.

72 Canto I. Verso 1087. Vid. C. García Gual, El viaje..., obra citada.
} 
lógicos, ya que el viaje de ida de los Argonautas y la salida de la escuadra tuvo lugar al principio del otoño ${ }^{73}$ (Fig. 10B).

Pero el empleo de este viejo mito, ejemplo de cuento de aventuras y relato geográfico, no quedaba sólo como un mero paralelismo en el espacio: una serie de mensajes de diversa índole se leen en el empleo de sus escenas y personajes.

El carácter de cruzada, incluso con sus tintes religiosos, viene dada por la concesión del Papa Pío $V$ de las mismas indulgencias que se concedian a los cruzados medievales. Esta nueva Argonáutica se justifica por lograr el fin de ese terrible dragón que es el peligro turco. Esta cruzada se justifica por la fe cristiana cuyas virtudes cardinales se concilian con los mitos clásicos, alumbradas por las teologales que se expresan en los fanales ${ }^{74}$.

La exaltación de España nos parece también clara: España consiguió la jefatura de esta Liga en la que había galeras del Papa y de Venecia. Los símbolos hispanos vienen a través de la repetición del mito de Hércules, y más claramente en el relieve del jardín de las Hespérides, míticamente relacionado con la Península, y la alusión a las empresas hispanas, colonizadoras y evangelizadoras. La Galera Capitana se constituye asi como un símbolo de España, Nueva Argos dirigida por un príncipe de la Casa Real, proyecto regio y por tanto de gran calidad artística y erudita. Esta exaltación viene unida a la de la Casa Imperial de Austria, a través de uno de sus más significativos símbolos: la orden del Toisón de Oro. No es casualidad que se eligiera este viaje de la Argonáutica, ya que es el que mejor encaja en los propósitos de exaltación política. El dorado vellocino, objeto de la más antigua Orden del Imperio, será el tesoro simbólico que hay que recuperar para rehacer la quebrada armonía del imperio cristiano universal.

$Y$ al Toisón de Oro se alude hasta en un plato del banquete festivo, a propósito de una pierna de carnero ${ }^{75}$ : "Se trae en la Milicia del Toisón... unos opinan que viene de Jasón, otros que de Gedeón...", en cuyo dilema el autor no toma partido. En esos momentos el maestrazgo de la Orden del Toisón de Oro recaía en Felipe II, representante de la Casa Real de Austria, al que repetidamente se elogia también de forma explícita.

\footnotetext{
73 Descripción..., obra citada, pág. 468.

Descripción..., obra citada, pág. 499.

Descripción..., obra citada, pág. 206.
} 
El vellocino desde la Biblia ${ }^{76}$ es una señal divina, signo de predestinación, que pasa a la mitología griega en la hazaña de Jasón. Hay en el hecho de comparar a D. Juan con Jasón un aire de predestinación, sobre aquél joven de 26 años, capaz de grandes hazañas, paladin de la cristiandad *.

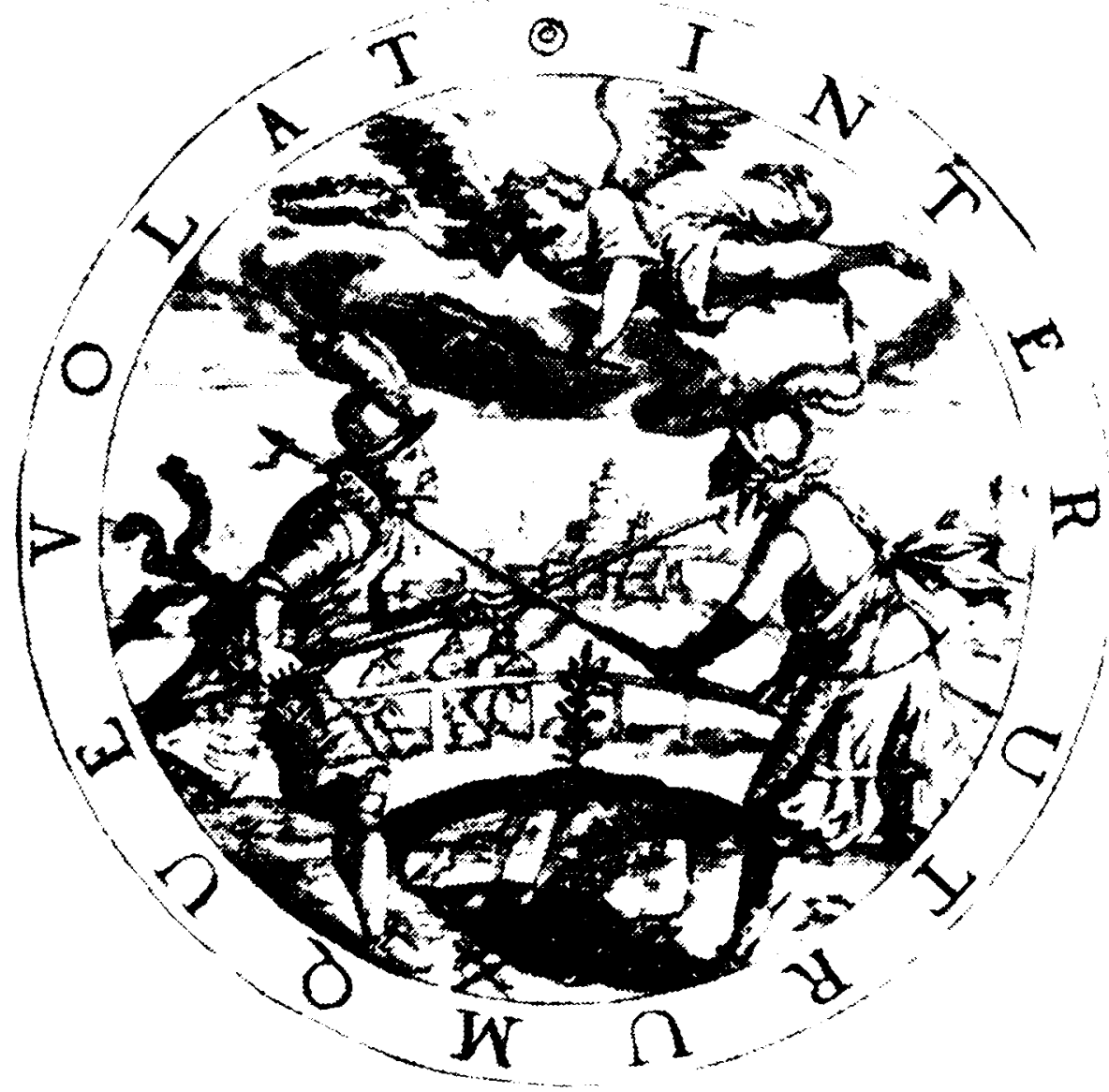

Fig. 1. Mote de Ulises en la arrumbada de proa. Rollenhagen n. 96.

76 Jueces 6.36.40,

* Este trabajo se presentó al Congreso Nacional de Historia del Arte de Santiago de Compostela en 1986. 

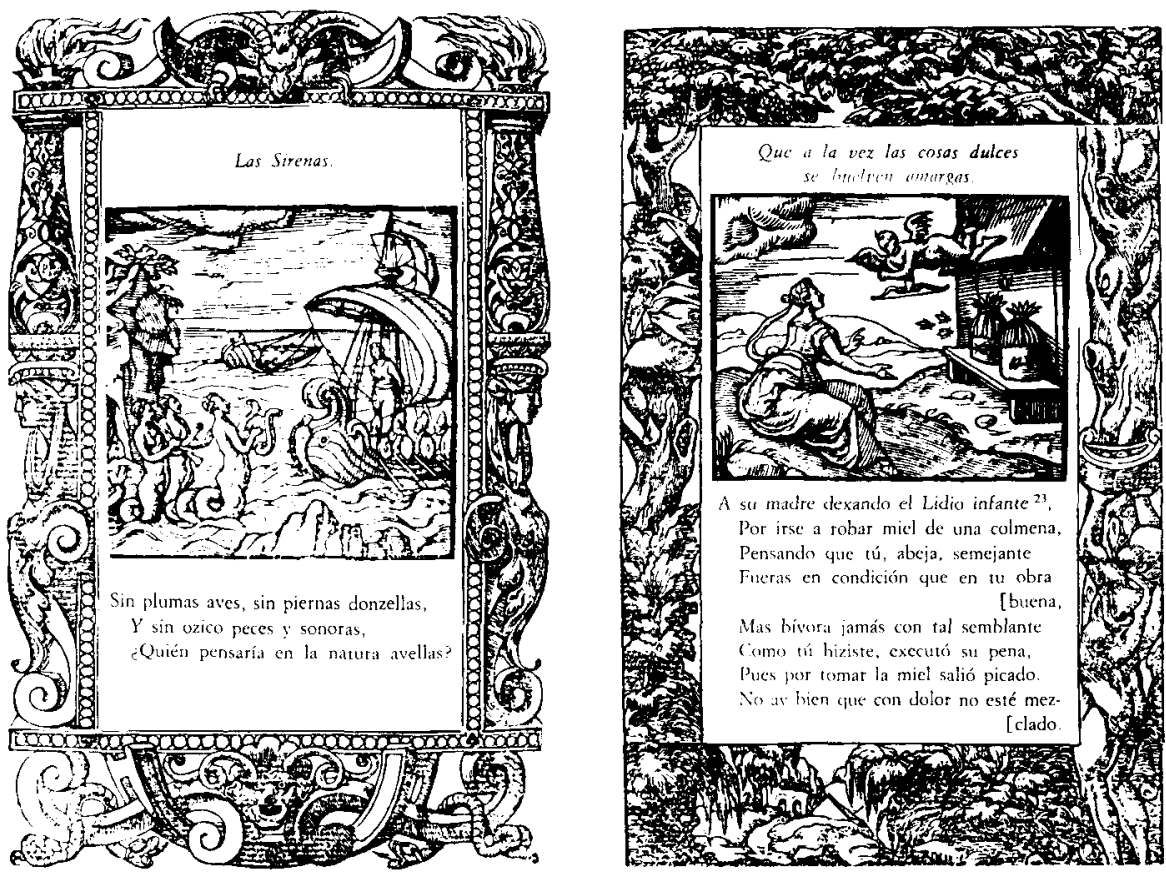

Fig. 2. Ulises en la banda lateral: Emblema CXV Alciato y Mote Emblema CXI Alciato. 


\begin{tabular}{|c|c|c|c|c|c|c|c|}
\hline$\frac{i}{5}$ & JASON & 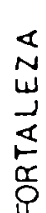 & NAVE & ARGOS & $\begin{array}{l}\frac{a}{2} \\
\frac{d}{d} \\
\frac{a}{2} \\
w \\
r\end{array}$ & $\begin{array}{l}\text { NAVE ENTRE } \\
\text { ESCOLLOS }\end{array}$ & 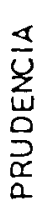 \\
\hline
\end{tabular}

Fig. 3. Esquema de la popa.

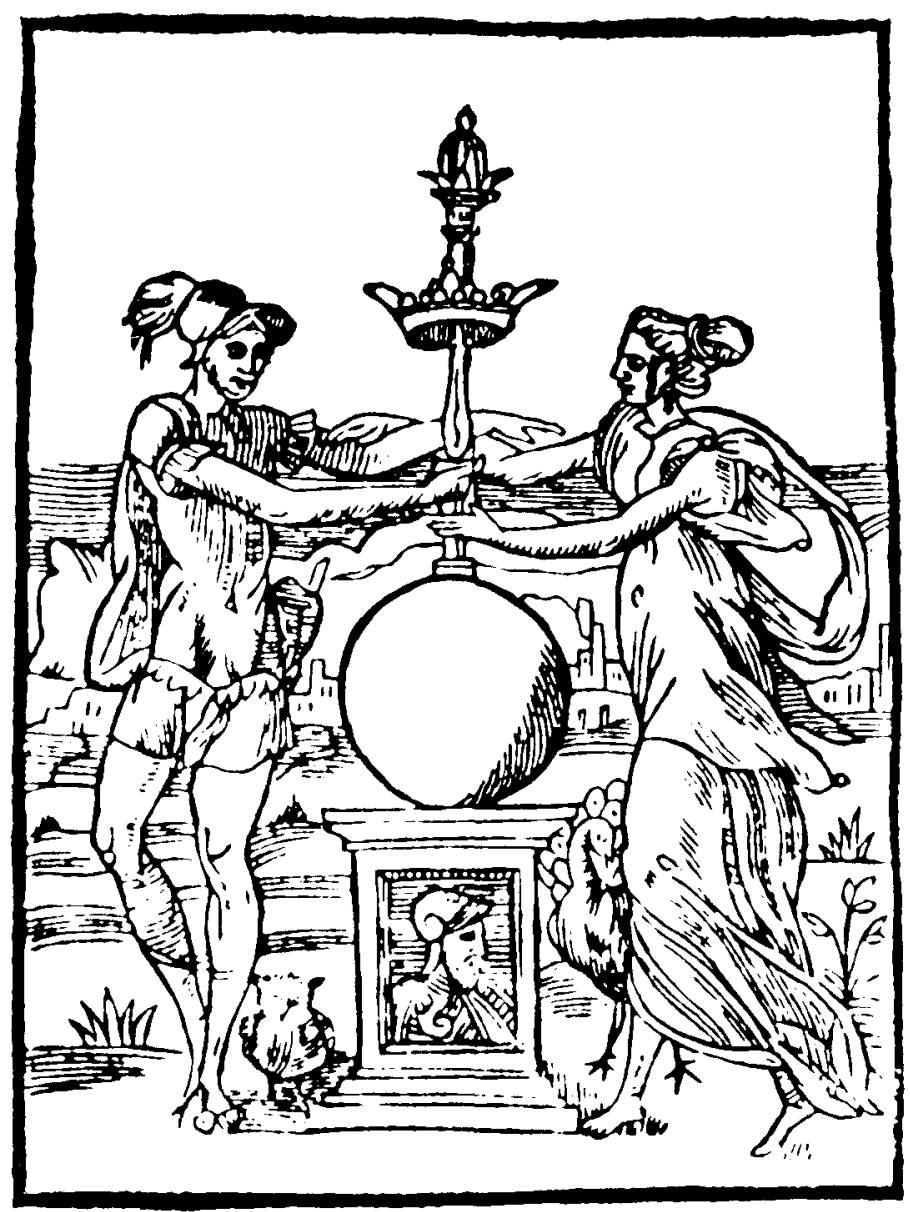

Fig. 4. Juno y Minena. Perriere. G. N. 18. 
El barco como objeto artístico y viaje alegórico...

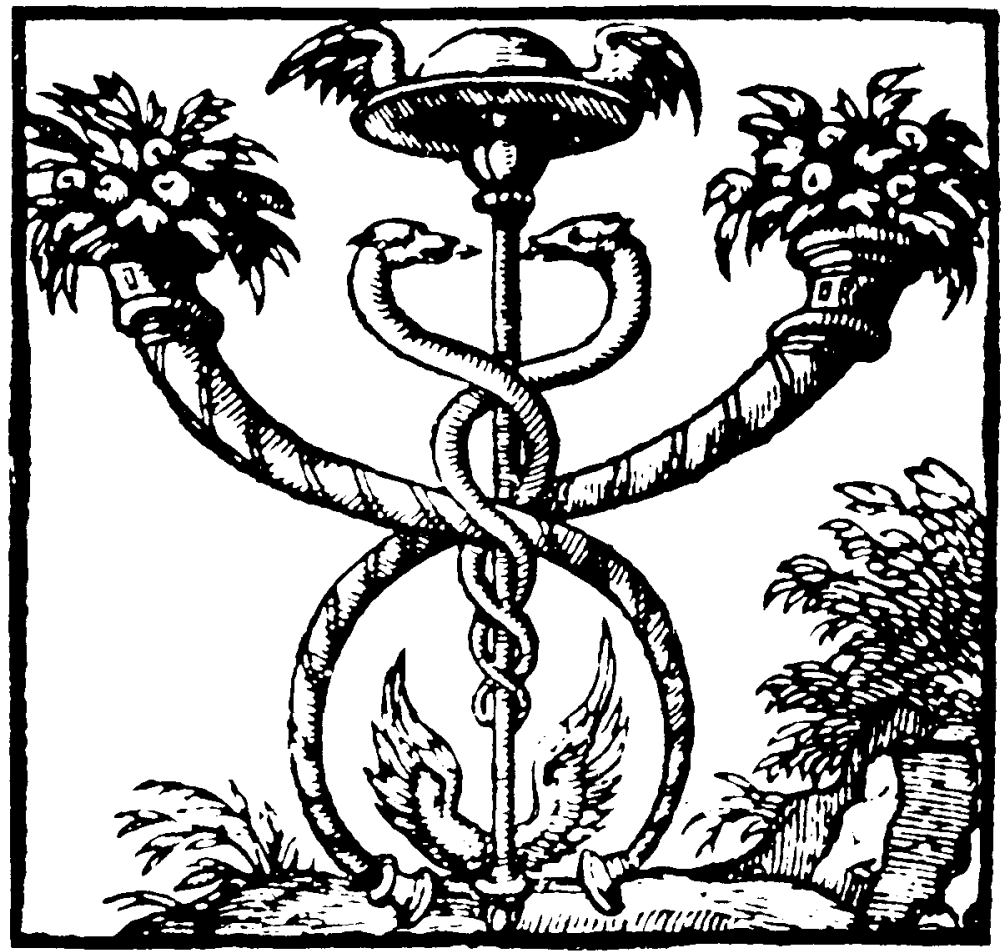

Fig. 5. La Fortuna y la Virtud. Emblema CXVIII Alciato.

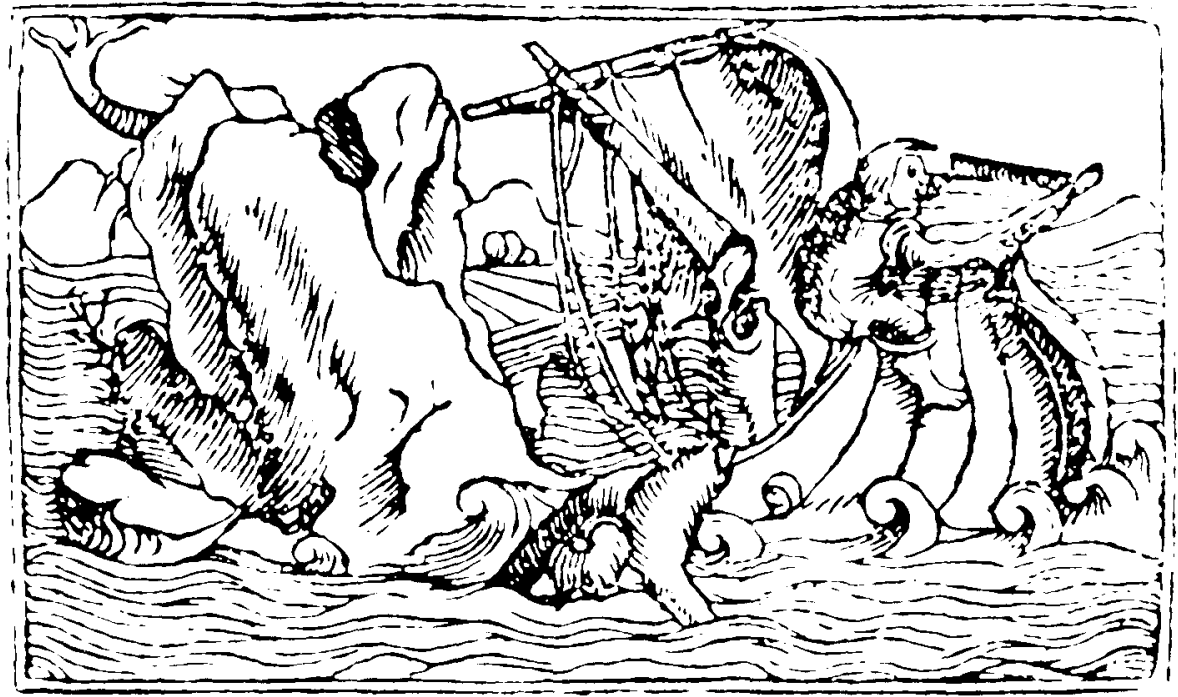

Fig. 6. Galera entre escollos. Corrozet. G. 


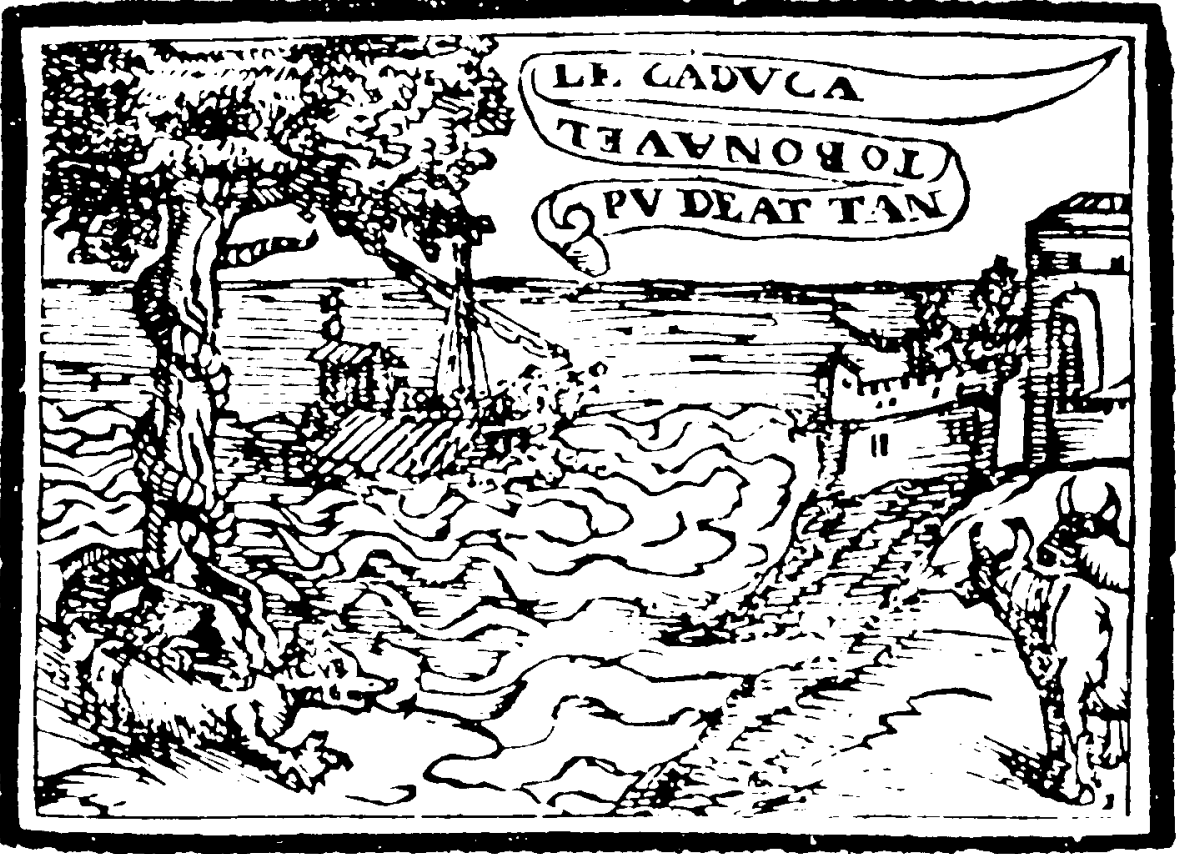

Fig. 7. Covarrubias Cent. III N. 89.

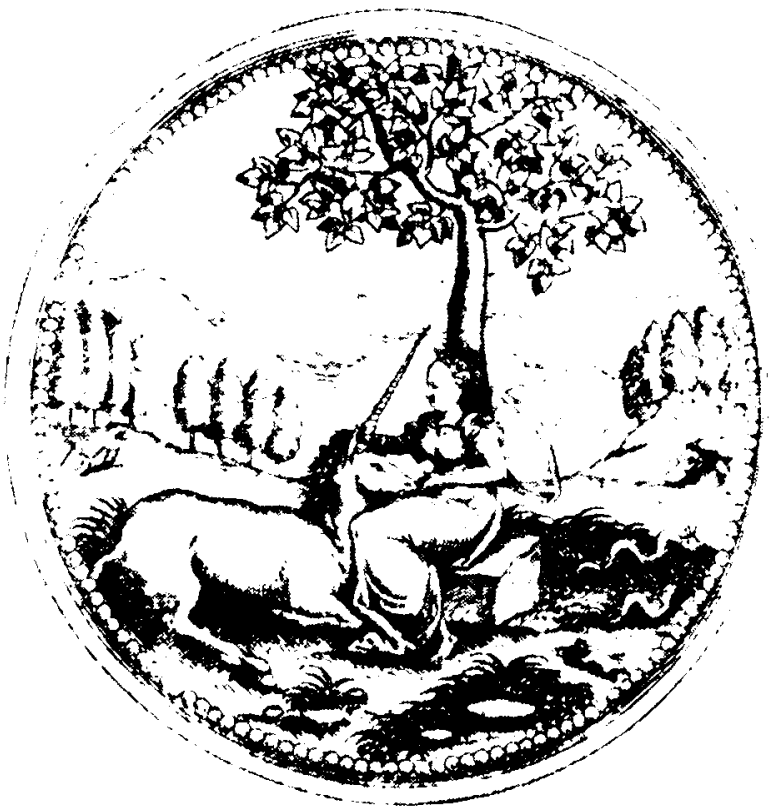

Fig. 8. Camerarius. Emblema 13. 

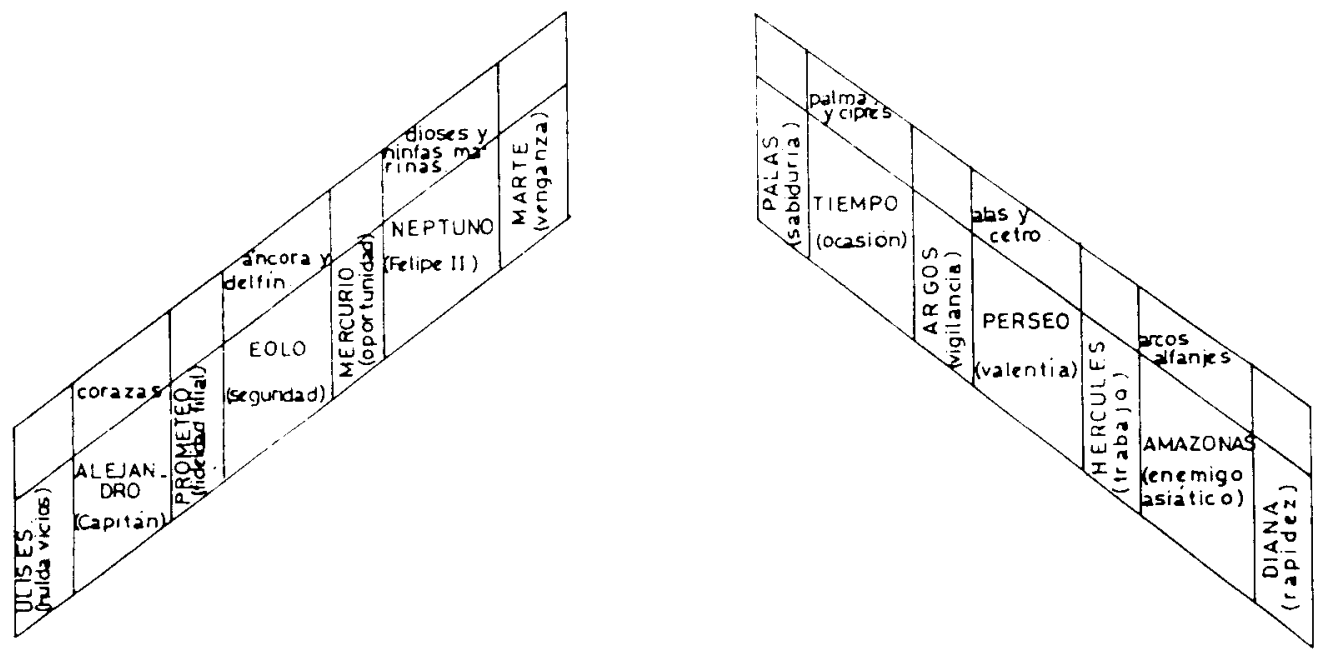

Fig. 9. Esquema de las bandas laterales: Palas en la banda de Estribor.

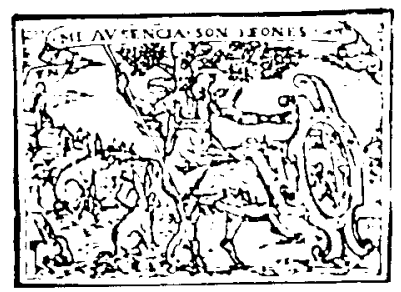

Fig. 10 a) Covarrubias. Cent. III N. 12: Hispania. 


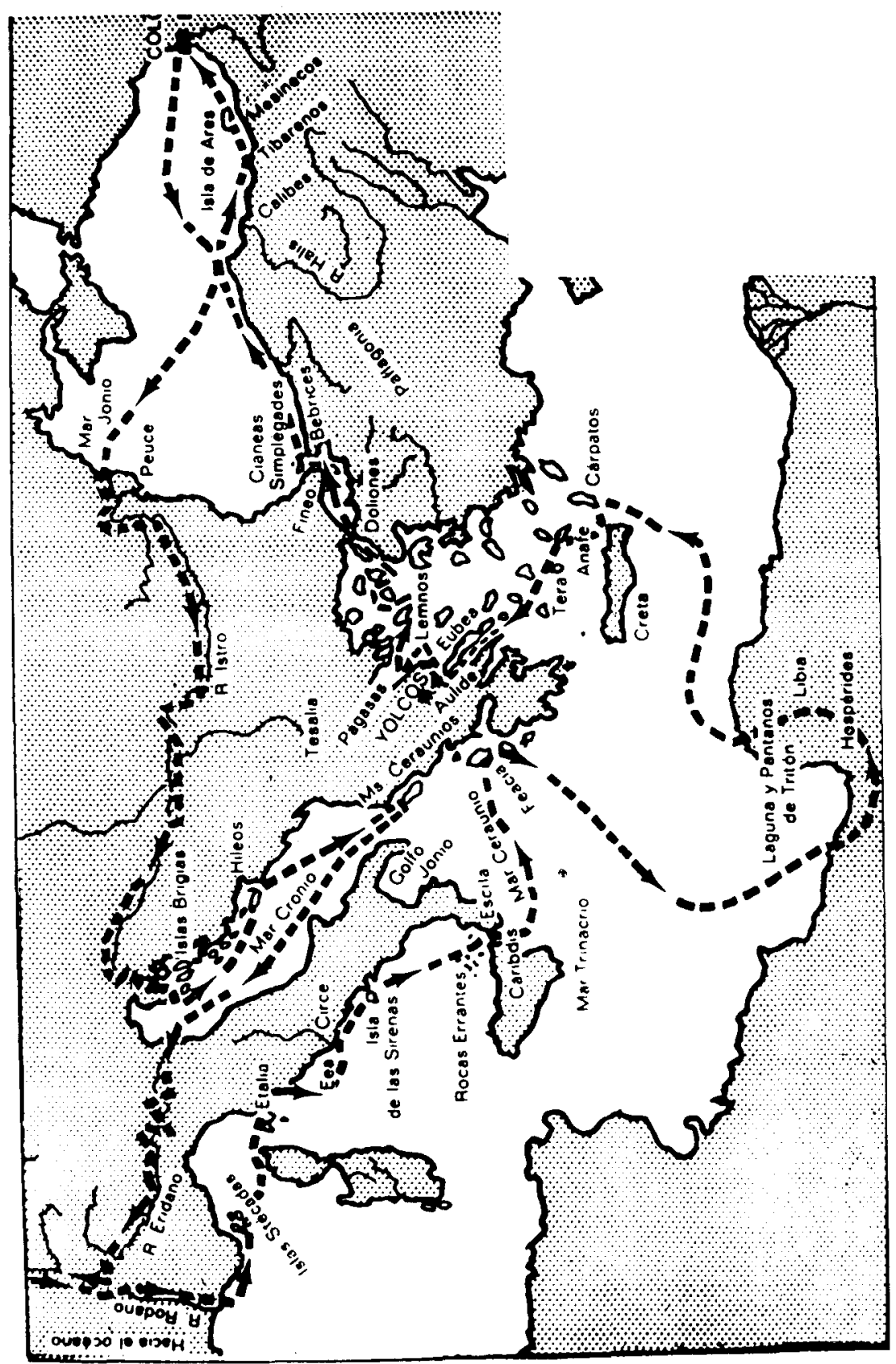

Fig. 10 b) Viaje de los Argonautas. 


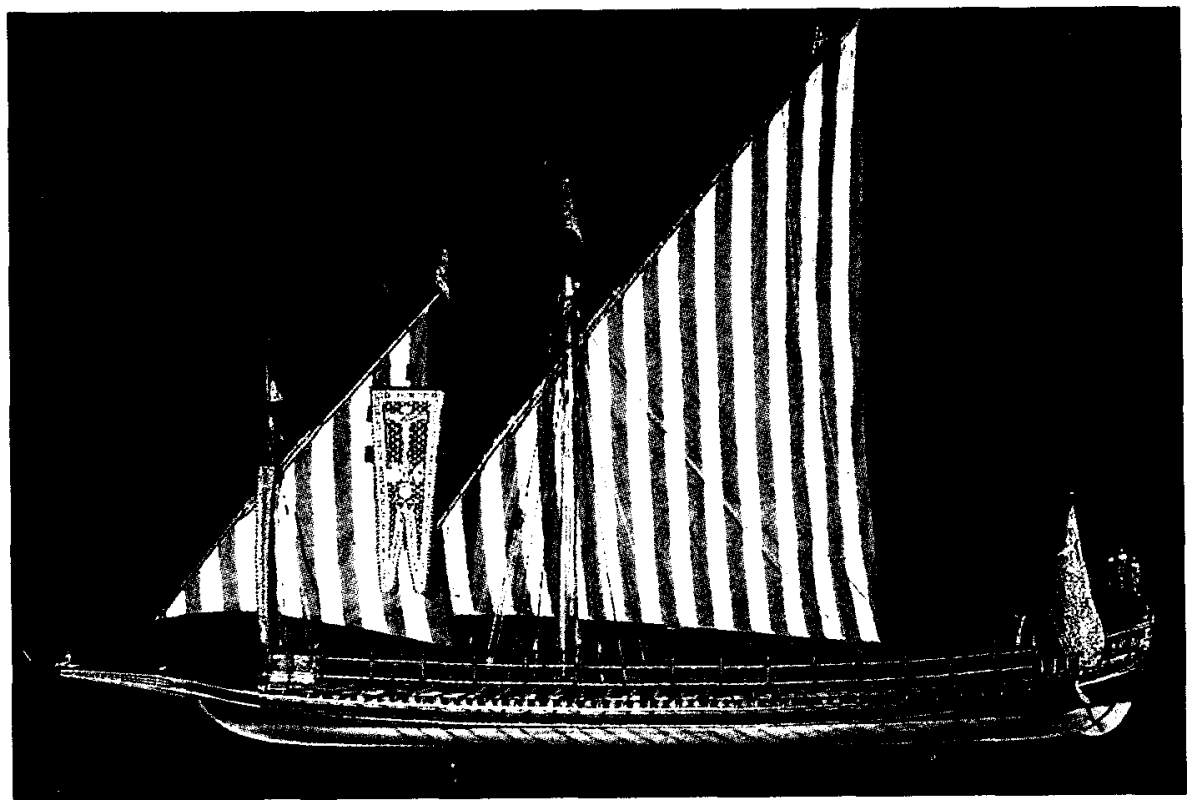

Fig. 11. Maqueta de la Galera Real de Lepanto. Reconstrucción Museo Maritimo de Barcelona Proa con la figura de Neptuno cabalgando en un delfín.

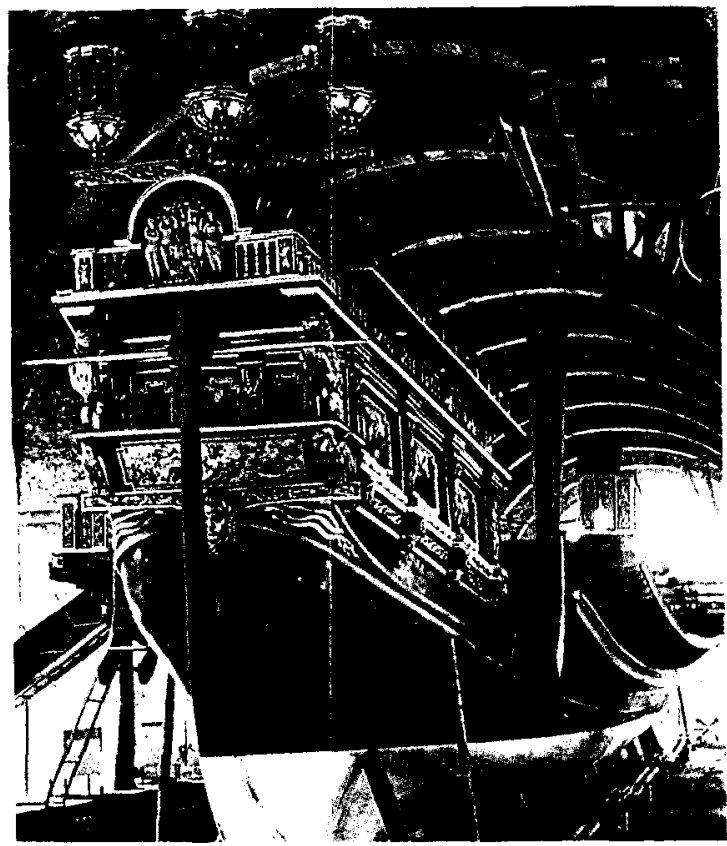

Fig. 12. Popa de la Galera Real reconstruida en el Museo Maritimo de Barcelona. 


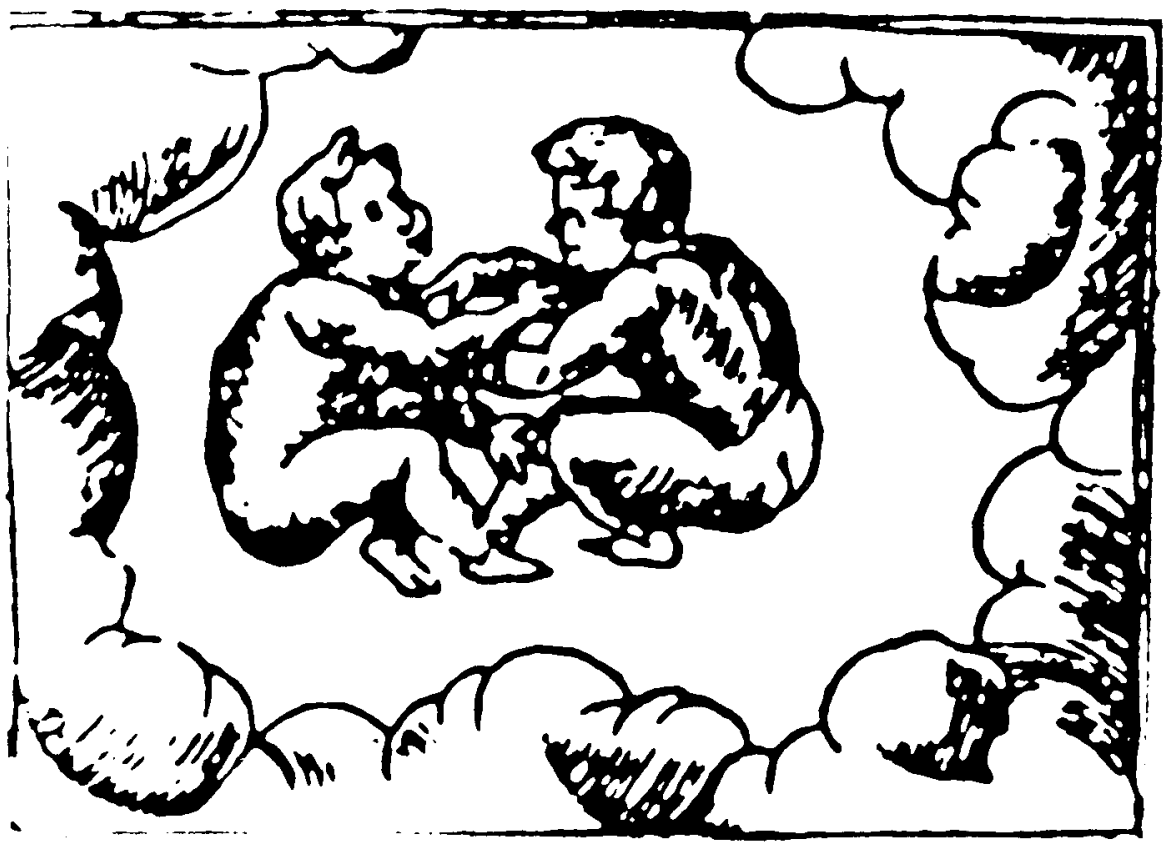

Fig. 13. Hernando de Soto, 120.

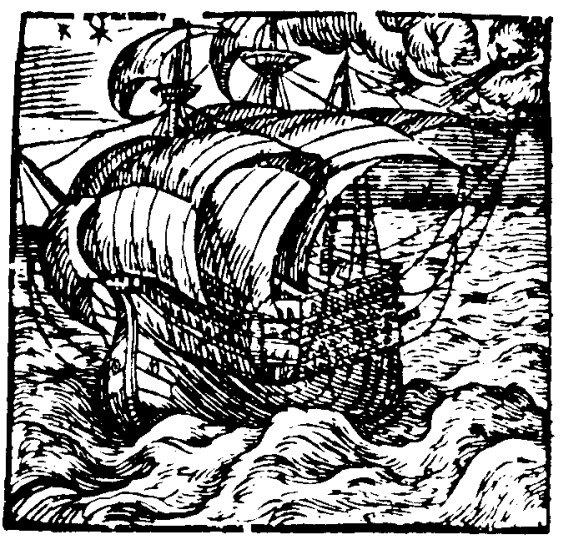

Fig. 14. Alciato. Emblema XLIII.

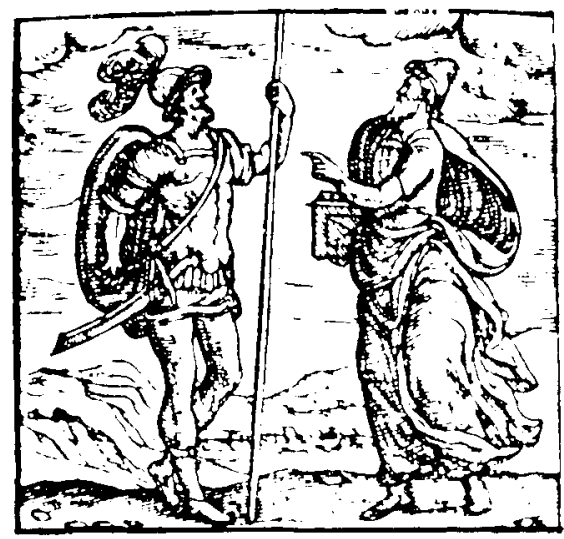

Fig. 15. Alciato. Emblema $X L I$. 